Arzttermin verpasst

\title{
Patient muss zahlen
}

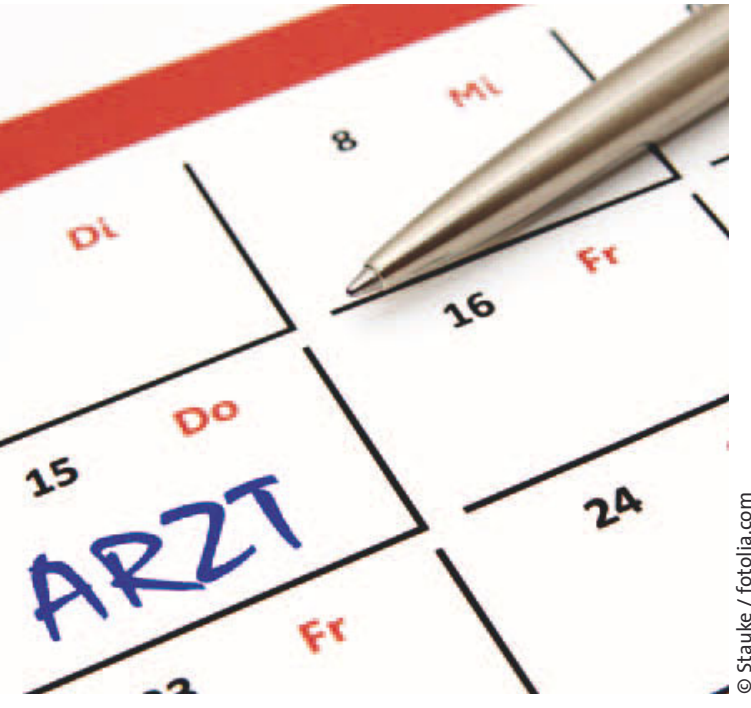

Termin beim Arzt: Sagen Patienten nicht rechtzeitig ab, kann der Arzt unter gewissen Umständen auf einer Ausfallzahlung bestehen.
— Eigentlich hätte er eine Gastroskopie gehabt - doch weil der Mann den Termin bei seiner Ärztin aus Euskirchen nicht eingehalten hat, wollte sie Ausfallkosten dafür haben. Zu Recht, wie jetzt das Landgericht Bonn entschied. Der Termin zur Magenspiegelung sei bereits im März 2008 für den darauffolgenden April vereinbart worden, berichtet der Bonner „General Anzeiger“. Auf dem Zettel sei darauf hingewiesen worden, dass Termine bei einer Verhinderung rechtzeitig abgesagt werden müssten. Auch im Wartezimmer der Ärztin habe ein Schild deutlich darauf hingewiesen. Dem sei der Mann aber nicht nachgekommen.

Die Ärztin schickte dem Patienten daraufhin eine Rechnung über 50 Euro, die der unter Betreuung stehende Mann nicht zahlen wollte. So landete der Fall vor dem Amtsgericht, schreibt die Zeitung weiter.
Das wies die Klage der Ärztin ab. Zu Begründung hieß es: Für den Patienten bestehe keine Verpflichtung zum Ersatz dieser Aufwendungen. Dienste „höherer Art“ könnten jederzeit gekündigt werden.

Vor dem Bonner Landgericht legte die Ärztin Berufung gegen das Urteil ein. Das Gericht schlug einen Vergleich vor - laut „General Anzeiger“, weil es Widersprüche in den Angaben des Patienten sah, wann er den Termin abgesagt haben will. Für die Richter am Landgericht könnte der Patient sich durchaus einer „Pflichtverletzung" schuldig gemacht haben. Denn auch er habe die Pflicht zur Rücksichtnahme. Eine ordentliche Terminabsage sei schon deswegen nötig, damit die behandelnden Ärzte ihre Termine und Praxisabläufe planen könnten. Der Mann zahlte im Rahmen des Vergleichs schließlich 20 Euro an die Ärztin.

\section{Verdacht auf Kindesmisshandlung}

\section{Ärzte sollen Hinweise weitergeben dürfen}

_ Ärzte und Psychologen sollen künftig von ihrer Schweigepflicht entbunden werden, wenn es "gewichtige“ Hinweise auf eine Kindesmisshandlung in der Familie gibt. Die Ärzte dürfen dann Informationen an das zuständige Jugendamt weitergeben.

Diese Neuregelungen sieht der Entwurf der Bundesregierung für ein Bundeskinderschutzgesetz vor, den Familienministerin Kristina Schröder (CDU) im Dezember in Berlin vorgestellt hat. Mit dem Gesetz sollten bislang unterschiedliche Regelungen in den Bundesländern zur Schweigepflicht von Ärzten und Psychologen bei Verdacht auf Gefährdung des Kindeswohls ,auf eine einheitliche Grundlage“ gestellt werden, sagte Schröder. Das Kinderschutzgesetz habe zum Ziel, einerseits die „enge Vertrauensbeziehung" zwischen Arzt und Patient zu schützen und gleichzeitig eine „Brücke zum Jugendamt“" zu bauen. Unter Kinderärzten ist die geplante Lockerung der Schweigepflicht nicht unumstritten. Einige Ärzte befürchten, dadurch könne das Vertrauensverhältnis zum Patienten nachhaltig gestört werden. Andere wiederum erwarten sich von der Regelung größere Rechtssicherheit. Im vergangenen Jahr waren bundesweit 3.490 Fälle von Misshandlungen von Kindern unter 14 Jahren bei den Polizeibehörden gemeldet worden. Die Dunkelziffer dürfte ungleich höher liegen. Schon 2008 hatte die große Koalition einen Entwurffür ein Kinderschutzgesetz erarbeitet. Dieser war jedoch bei Experten auf massive Kritik gestoßen und im anschließenden Bundestagswahlkampf untergegangen. Schröder versicherte nun, sie habe bei ihrem Entwurf für ein Kinderschutzgesetz die Empfehlungen von Fachleuten und Wissenschaftlern, Ländern und Kommunen einbezogen. Der Dialog habe sich gelohnt. Daher habe das neue Bundeskinderschutzgesetz, das zum 1. Januar 2012 in Kraft treten soll, ,,seinen Namen wirklich verdient".

hom
PKV

\section{Neuer Ombudsmann}

_Dr. Klaus Theo Schröder ist seit 1. Januar 2011 neuer Ombudsmann für die private Krankenund Pflegeversicherung (PKV). Er gilt als ausgewiesener Kenner des Gesundheitswesens. Ein Thema, das er intensiv begleitet hat, ist die elektronische Gesundheitskarte (eGK). Die gematik-Gesellschafter haben inn in diesem Frühjahr zum Schlichter bei Auseinandersetzungen rund um die eGK gemacht. „Theo Schröder hat eine hohe Sachkunde, kennt die unterschiedlichen Ecken des Gesundheitswesens und ist breit akzeptiert", sagte der Direktor des PKV-Verbands Dr. Volker Leienbach. Aufgabe des Ombudsmanns ist es, bei Streitfällen zwischen PKV-Unternehmen und Kunden zu vermitteln. Er kann Empfehlungen aussprechen, die jedoch nicht bindend sind. Vorgänger Dr. Helmut Müller wollte seine Amtszeit aus Altersgründen nicht verlängern. Seine Arbeit habe dazu beigetragen, dass die Institution des Ombudsmannes sich ,hohes Ansehen und großes Vertrauen bei den Versicherten " erworben habe, lobte der Vorsitzende des PKV-Verbands Reinhold Schulte. iss 